\title{
Chapter 4 \\ Exploring the Relationship Between Heat Absorption and Material Thermal Parameters for Thermal Energy Storage
}

\author{
Law Torres Sevilla and Jovana Radulovic
}

\begin{abstract}
Using thermal energy storage alongside renewables is a way of diminishing the energy lack that exists when renewable energies are unable to run. An indepth understanding of the specific effect of material properties is needed to enhance the performance of thermal energy storage systems. In this paper, we used fitting models and regression analysis to quantify the effect that latent heat of melting and material density have on the overall heat absorption. A single tank system, with encapsulated phase change materials is analysed with materials properties tested in the range of values commonly found in the literature. These materials are, therefore, hypothetically constructed ones based on materials such as paraffin. The software used for the numerical analysis is COMSOL Mulitphysics. Results show that the relationship between the latent heat and density regarding heat absorbed is a positive linear function for this system.
\end{abstract}

Keywords Thermal storage $\cdot$ Energy $\cdot$ Materials $\cdot$ Graph fitting

\subsection{Introduction}

Every day the world is facing energy challenges whilst we further develop the use and implementation of renewables. Although these green technologies help stray away from fossil fuel usage, there are some major drawbacks. One is the intermittency issue, as they are only as effective as the weather allows them to be. However, combining thermal energy storage (TES) alongside them is a way of diminishing the mismatch between supply and demand.

Thermal energy storage systems can be divided into sensible heat, latent heat and thermochemical. This paper focuses on the combination of the first two. Sensible heat stores heat per degree increased, whereas latent heat stores heat during a phase change [1]. Sensible heat is the most used storage and the material selection is based on properties such as specific heat capacity, density and thermal conductivity. Latent heat

L. T. Sevilla $(\bowtie) \cdot$ J. Radulovic

School of Mechanical and Design Engineering, University of Portsmouth, Anglesea Building,

Anglesea Road, Portsmouth PO1 3DJ, UK

e-mail: law.torressevilla@ port.ac.uk

I. Mporas et al. (eds.), Energy and Sustainable Futures, Springer Proceedings in Energy, https://doi.org/10.1007/978-3-030-63916-7_4 
offers an advantage over sensible heat in terms of narrower operating temperatures and high energy density, requiring a material selection based on properties such as melting temperature and latent heat [2]. The most common type of latent heat is solid-liquid, hence why the analysis is on this particular one [3]. This paper focuses on parameters relevant to the heat absorption output, such as density (for sensible heat) and latent heat of melting (for latent heat). Designs for these are generally packed beds, single/double tank systems and heat exchangers. Common materials as storage mediums for sensible heat include solids such as rocks, ceramics, concrete, or fluids such as water, oils and inorganic salts [4]. For latent heat, materials used are classified into organic (paraffins, fatty acids and eutectics) and inorganic (salt hydrates and eutectics) [5]. Phase changing materials (PCMs) should have a number of desirable properties, amongst others: high thermal conductivity to enhance the heat transfer; they should be chemically stable, non-toxic or flammable; low cost and high availability are naturally advantageous [6]. Latent heat of melting and density are of vital importance for the performance of a TES. It is known that higher values lead to improved system performance. The aim of this study is to quantify the relationship between these thermal parameters and the heat absorption of a single tank system. This information can help in real life applications to aid users in material selection, material enhancement and contribute towards optimization of TES systems.

Parhizi et al. [7], similarly to the aim of this paper, assess the impact of thermal properties on a PCM based TES system for two models: a simplified cartesian 1D one and a cylindrical 3D one. They propose a theoretical heat transfer model, which aims to predict the rate of energy stored and energy density as functions of the thermal conductivity. Their results indicate that there is bound to be a trade-off when selecting the material. They report that while increasing thermal conductivity improves the rate of energy stored, the energy storage density itself does not change for the cartesian system and decreases for the cylindrical system.

\subsection{Methodology}

\subsubsection{System Design}

The analysed system consists of a symmetrical single cylindrical tank, packed with encapsulated and spherical PCMs. The tank height and length are $0.5 \mathrm{~m}$ and packed with a set of $19 \times 17$ encapsulated spheres containing the selected PCM. The tank frame is $0.025 \mathrm{~m}$ thick and the capsule is considered thin and negligible, with the sphere radius of $0.0125 \mathrm{~m}$. It has a centric single inlet and outlet of dimensions $0.12 \mathrm{~m}$ and is symmetrical. The HTF is water and enters the system at a constant temperature of $90{ }^{\circ} \mathrm{C}$ and at a velocity of $0.01 \mathrm{~m} / \mathrm{s}$. The tank initially has still water inside at an ambient temperature of $20^{\circ} \mathrm{C}$. The analysis focuses on the centre point of the system, at coordinates $(0,0)$ where the centre sphere is. The analysis was carried 

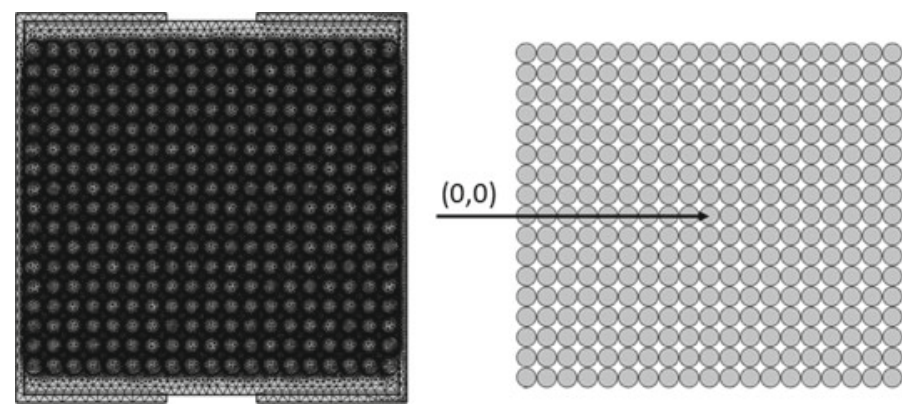

Fig. 4.1 System design meshed in COMSOL Multiphysics and coordinates $(0,0)$

out in COMSOL Multiphysics and the system was approximately 140,000 elements, mostly triangular prisms (Fig. 4.1).

\subsubsection{Boundary Conditions and Assumptions}

The 2D simulation is run in COMSOL Multiphysics for $60 \mathrm{~min}$ in $1 \mathrm{~min}$ step intervals. The model uses the "Laminar Flow" and "Heat Transfer in Fluids" physics, alongside the "Nonisothermal Flow" multi-physics. The numerical problem was solved using Fourier's Law and the heat equation for non-uniform isotropic mediums. Heat absorbed will then be calculated using Eq. 4.3.

$$
\begin{gathered}
\rho C_{p} \frac{\partial T}{\partial t}+\rho C_{p} u \cdot \nabla T+\nabla \cdot q=Q+Q_{p}+Q_{v d} \\
q=k \nabla T \\
q=m(C p s \cdot(T m-T i)+L+(T f-T m) \cdot C p l)
\end{gathered}
$$

where $\rho$ is density, $\mathrm{Cp}$ is heat capacity at constant pressure (subscripts " $\mathrm{s}$ " and "l" indicate solid and liquid phases), $\mathrm{T}$ is temperature (subscripts " $\mathrm{m}$ ", " $\mathrm{i}$ " and "f" indicate melting, initial and final), $t$ is time, $u$ is velocity, $q$ is heat flux, $Q$ is the heat source, Qp is heat pressure work, Qvd is heat viscous dissipation and $\mathrm{k}$ is thermal conductivity.

The inlet boundary layer is velocity and the outlet is pressure, where initial pressure is zero and the model supress backflow. The wall boundary conditions are no slip and the tangential velocity is zero. The HTF is modelled to be laminar and incompressible and all materials are homogeneous and isotropic. Furthermore, there 
Table 4.1 Material properties and their ranges for the tested hypothetical analysis

\begin{tabular}{l|l|l|l|l|l}
\hline & Base Case & Variation 1 & Variation 2 & Variation 3 & Variation 4 \\
\hline Melting temperature & $45^{\circ} \mathrm{C}$ & $45^{\circ} \mathrm{C}$ & $45^{\circ} \mathrm{C}$ & $45^{\circ} \mathrm{C}$ & $45^{\circ} \mathrm{C}$ \\
\hline Latent Heat & $200 \mathrm{~kJ} / \mathrm{kg}$ & $10 \mathrm{~kJ} / \mathrm{kg}$ & $500 \mathrm{~kJ} / \mathrm{kg}$ & $200 \mathrm{~kJ} / \mathrm{kg}$ & $200 \mathrm{~kJ} / \mathrm{kg}$ \\
\hline Density & $800 \mathrm{~kg} / \mathrm{m}^{3}$ & $800 \mathrm{~kg} / \mathrm{m}^{3}$ & $800 \mathrm{~kg} / \mathrm{m}^{3}$ & $600 \mathrm{~kg} / \mathrm{m}^{3}$ & $1000 \mathrm{~kg} / \mathrm{m}^{3}$ \\
\hline
\end{tabular}

are no heat losses due to radiation and the outer wall of the tank is perfectly insulated. Lastly, the encapsulated spheres are modelled to be circles that do not undergo deformation.

\subsubsection{Materials and Analysis}

The materials used in this experiment are non-existing and hypothetical. They were constructed using informed, reasonable and educated values from materials found in systems and found in the literature. The base case is based on standard paraffin properties. In all simulations the melting temperature $\left(45^{\circ} \mathrm{C}\right)$, thermal conductivity ( $0.4 \mathrm{~W} / \mathrm{mK}$ solid and $0.2 \mathrm{~W} / \mathrm{mK}$ liquid), and specific heat capacity $(2000 \mathrm{~J} / \mathrm{kgK}$ solid and $2200 \mathrm{~J} / \mathrm{kgK}$ liquid) were the same, yet density and latent heat were varied as shown in Table 4.1.

\subsection{Results}

Using the temperatures recorded for the centre sphere, the heat absorbed was calculated and a regression analysis was performed. Results shown in Figs. 4.2 and 4.3 indicate a linear relationship in both cases.

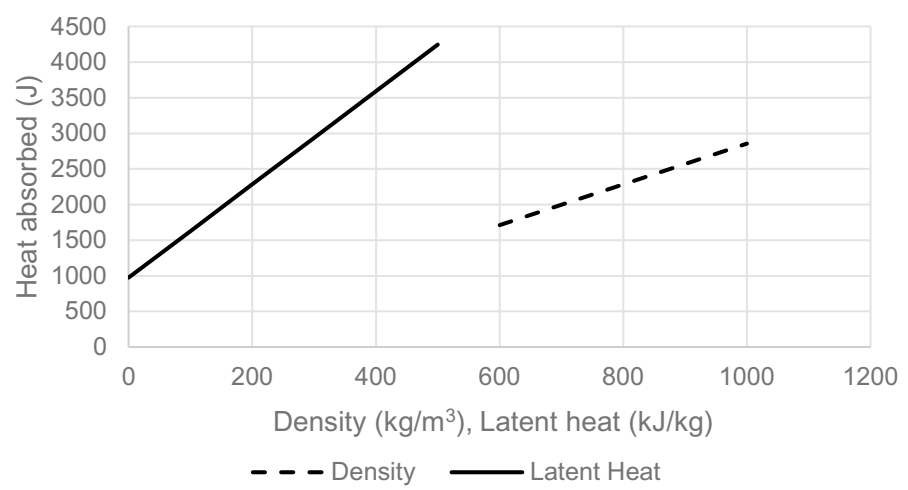

Fig. 4.2 Line plot of the heat absorbed (after $60 \mathrm{~min}$ ) against latent heat and density 


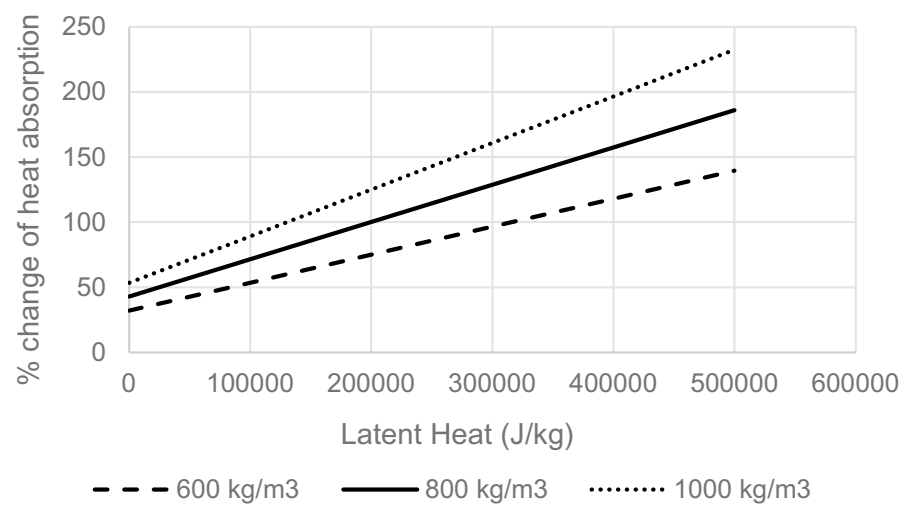

Fig. 4.3 Percentage change of the heat absorbed compared to the base case

\subsection{Discussion}

Both high density and latent heat yield higher heat absorption values.

The change in latent heat shows a much wider range in values, where the maximum and minimum are 4247.39 $\mathrm{J}$ and $1040.65 \mathrm{~J}$ (a difference of $3206.74 \mathrm{~J}$ ), respectively. For density, the range was from $2854.88 \mathrm{~J}$ to $1713.14 \mathrm{~J}$ (a difference of $1141.74 \mathrm{~J}$ ). This shows an increase from the minimum value of $308 \%$ for latent heat and $66 \%$ for density, approximately. Across the tested range, a relative increase of heat absorbed per $100 \mathrm{~kJ} / \mathrm{kg}$ of latent heat was $6.5 \mathrm{~kJ}$, compared to $2.9 \mathrm{~kJ}$ of heat absorbed per $100 \mathrm{~kg} / \mathrm{m}^{3}$ of density increase, showing that for low temperature heat storage the latent heat is a more influential factor. By increasing latent heat by $10 \%$ from the base case, the relative increase in heat absorption is $28 \%$. In comparison, $24 \%$ increase is seen by density rise to $1000 \mathrm{~kg} / \mathrm{m}^{3}$ from $800 \mathrm{~kg} / \mathrm{m}^{3}$.

Paraffins and organic PCMs have desirable density values. However, high latent heat values considered in this study are outside the conventional range. While the addition of nanoparticles is a promising method for an alternation of the latent heat of PCMs [8], in practical systems it is beneficial to use high density PCMs to maximise heat absorption. While this increases the weight of the tank, if the volume variation during phase change is relatively low, the tank volume does not present a challenge.

\subsection{Conclusion}

In conclusion, increasing the latent heat and density without altering any other system parameters gives a simple linear relationship regarding heat absorption. Higher latent heat is a more influential parameter, although practically the same effect can be achieved with a material with higher density. 


\section{References}

1. J.A. Almendros-Ibáñez, M. Fernández-Torrijos, M. Díaz-Heras, J.F. Belmonte, C. Sobrino, A review of solar thermal energy storage in beds of particles: packed and fluidized beds. Sol. Energy 192, 193-237 (2019). https://doi.org/10.1016/j.solener.2018.05.047

2. E. Guelpa, V. Verda, Thermal energy storage in district heating and cooling systems: a review. Appl. Energy 252, 113474 (2019). https://doi.org/10.1016/j.apenergy.2019.113474

3. A. Fallahi, G. Guldentops, M. Tao, S. Granados-Focil, S. Van Dessel, Review on solid-solid phase change materials for thermal energy storage: Molecular structure and thermal properties. Appl. Therm. Eng. 127, 1427-1441 (2017). https://doi.org/10.1016/j.applthermaleng.2017.08.161

4. Q. Zhou, D. Du, C. Lu, Q. He, W. Liu, A review of thermal energy storage in compressed air energy storage system. Energy 188, 115993 (2019). https://doi.org/10.1016/j.energy.2019. 115993

5. A. Gil, M. Medrano, I. Martorell, A. Lazaro, P. Dolado, B. Zalba, L.F. Cabeza, State of the art on high temperature thermal energy storage for power generation. Part $1-$ concepts, materials and modellization. Renew. Sustain. Energy Rev. 14, 31-55 (2010). https://doi.org/10.1016/j.rser. 2009.07.035

6. I. Sarbu, C. Serbarchievici, A comprehensive review of thermal energy storage. Sustainability 10, 191 (2018). https://doi.org/10.3390/su10010191

7. M. Parhizi, A. Jain, The impact of thermal properties on performance of phase change based energy storage systems. Appl. Therm. Eng. 162, 114154 (2019). https://doi.org/10.1016/j.app lthermaleng.2019.114154

8. A. Sari, C. Alkan, A.N. Ozcan, Synthesis and characterization of micro/nano capsules of PMMA/capric-stearic acid eutectic mixture for low temperature-thermal energy storage in buildings. Energy Buildings 90, 106-113 (2015). https://doi.org/10.1016/j.enbuild.2015.01.013

Open Access This chapter is licensed under the terms of the Creative Commons Attribution 4.0 International License (http://creativecommons.org/licenses/by/4.0/), which permits use, sharing, adaptation, distribution and reproduction in any medium or format, as long as you give appropriate credit to the original author(s) and the source, provide a link to the Creative Commons license and indicate if changes were made.

The images or other third party material in this chapter are included in the chapter's Creative Commons license, unless indicated otherwise in a credit line to the material. If material is not included in the chapter's Creative Commons license and your intended use is not permitted by statutory regulation or exceeds the permitted use, you will need to obtain permission directly from the copyright holder. 